\title{
Image Based Sexual Abuse proclivity and victim blaming: The role of dark personality traits and moral disengagement
}

OÑATI SOCiO-Legal SeRIES, VOlume 11 Issue 5 (2021), 1179-1197: YOUTH VIOLENCE: DeESCALATION STRATEGIES AND SOCIO-LEGAL RESPONSES

DOI LINK: HTTPS://DOI.ORG/10.35295/OSLS.IISL/0000-0000-0000-1213

RECEIVED 12 OCTOBER 2019, ACCEPTED 05 JULY 2021

\author{
AFroditi PINA* iD \\ ALISHA BELL* \\ KIMBERLEY GRIFFIN* \\ EDUARDO A. VASQUEZ*
}

\section{Abstract}

Image Based Sexual Abuse (IBSA) denotes the creation, distribution, and/or threat of distribution of intimate images of another person online without their consent. The present study aims to extend emerging research on perpetration of IBSA with the development and preliminary validation for the moral disengagement in IBSA scale, while also examining the role of the dark triad, sadism, and sexism in a person's likelihood to perpetrate IBSA. One hundred and twenty English speaking participants (76 women, 44 men; mean age $=33$ years) were recruited via social media. Machiavellianism and psychopathy were found to predict IBSA proclivity, whilst rivalry narcissism predicted greater feelings of excitement and amusement towards IBSA. Moral disengagement predicted IBSA proclivity and blaming the victim. It was also positively related to greater feelings of amusement and excitement towards IBSA. This suggests a distinct personality profile of IBSA perpetrators, and that moral disengagement mechanisms play a role in facilitating and reinforcing this behaviour.

\section{Key words} tetrad

Image Based Sexual Abuse; IBSA; perpetrators; moral disengagement; dark

\footnotetext{
* Corresponding author: Afroditi Pina. Centre for Research and Education in Forensic Psychology (COREFP), School of Psychology, University of Kent. Email address: a.pina@kent.ac.uk

* Centre for Research and Education in Forensic Psychology (CORE-FP), School of Psychology, University of Kent.

* Kimberley Griffin holds an MSc in Forensic Psychology from the University of Kent and currently works as an Advanced KERS Worker (Kent Enablement Recovery Service) at Kent County Council.

* Centre for Research and Education in Forensic Psychology (CORE-FP), School of Psychology, University of Kent.
} 


\section{Resumen}

El abuso sexual basado en la imagen (ASBI) describe la creación, distribución y/o amenaza de distribución en Internet de imágenes íntimas de otra persona sin su consentimiento. Este estudio pretende extender la investigación emergente sobre la comisión de ASBI con el desarrollo y validación preliminar de la separación moral en la escala ASBI, al tiempo que se examina el papel de la tríada oscura, el sadismo y el sexismo en la probabilidad de que una persona cometa ASBI. Se reclutó mediante redes sociales a 120 participantes de habla inglesa (76 mujeres, 44 hombres, edad promedio de 33 años). Se concluyó que la personalidad maquiavélica y la psicopatía pueden predecir la proclividad de cometer ASBI, mientras que el narcisismo de rivalidad predecía mayores sentimientos de emoción y diversión hacia el ASBI. La desconexión moral predecía la proclividad al ASBI y la culpabilización de la víctima. También estaba positivamente relacionada con mayores sentimientos de diversión y emoción hacia el ASBI. Esto insinúa un perfil de personalidad concreto de las personas que cometen ASBI, así como que los mecanismos de desconexión moral desempeñan un papel a la hora de facilitar y reforzar esa conducta.

\section{Palabras clave}

Abuso Sexual Basado en la Imagen; ASBI; infractores; desconexión moral; tétrada oscura 


\section{Table of contents}

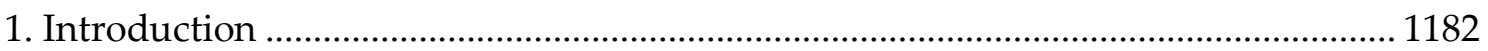

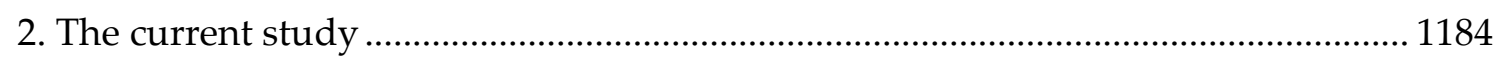

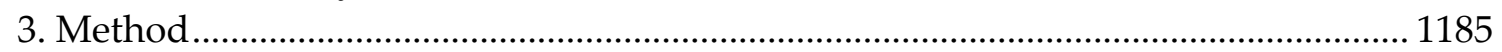

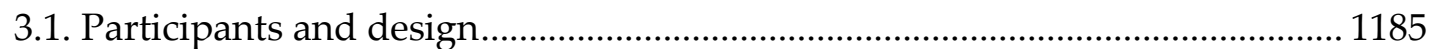

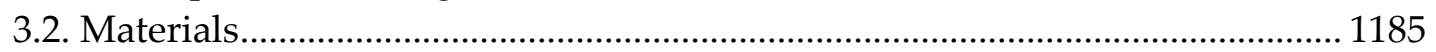

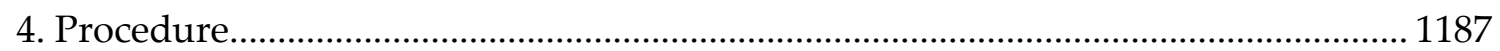

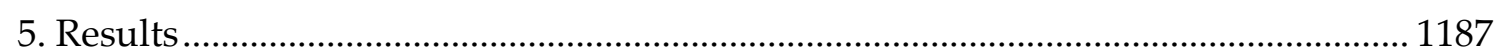

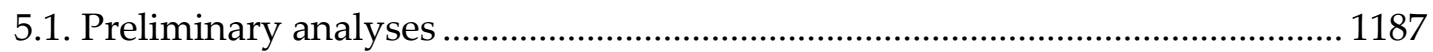

6. Moral disengagement in Image-Based Sexual Abuse .............................................. 1188

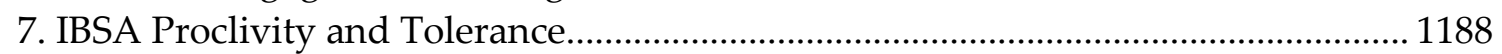

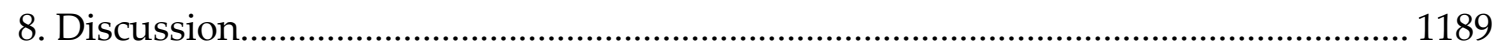

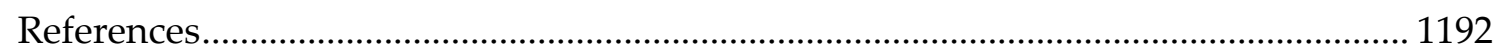

Appendix. Moral disengagement in image-based sexual abuse scale (MDiISA) ........ 1196 


\section{Introduction}

The ever-expanding developments and use of technology have facilitated new ways of social interaction. The internet has provided an important and valuable space for widespread communication, education, and mobilisation on important issues relating to sexual violence and victim blaming (Powell 2010, Rentschler 2014). Unfortunately, it is also being used as a medium for victimisation and sexual violence (Henry and Powell 2015b). This array of abusive behaviours has been termed technology facilitated sexual violence (TFSV) to reflect an extension of sexual violence, and that it often serves to maintain structural gender inequalities (Henry and Powell 2015b); the term acknowledges that whilst the majority of victims are female, males are also victims, and the abuse directed at both men and women is gendered and manifested in particular ways due to socially constructed gender ideologies regarding masculine and feminine behaviour (Powell and Henry 2018, 2019).

One form of TFSV of interest in this study is image-based sexual abuse (IBSA), (a form of which is colloquially known as "revenge porn" and referring to situations involving current or ex partners). IBSA refers to the non-consensual creation, distribution, or threat of distribution of intimate, sexual or nude photos or videos of another person online (McGlynn and Rackley 2017, Henry et al. 2019, Powell et al. 2019), sometimes with additional identifying information of the victim being shared alongside the footage (Tungate 2014). In some cases, the content has originally been obtained consensually and then later shared on the Internet without consent (Henry and Powell 2016). In other cases, the intimate image has been obtained non-consensually; for example, by means of hacking, superimposing the victims face onto a sexual image, or images being taken of the victim unconscious or during a sexual assault (Powell 2015, Henry and Powell 2016, Walker and Sleath 2017). The commonly thought of "revenge porn" scenario of IBSA is one of vengeful motivations, whereby an ex-partner posts images of their former partner to humiliate them (Citron and Franks 2014). However, research shows that revenge is not the only motivation, with people perpetrating IBSA for monetary and social status gain, sexual gratification, blackmail, and intimidation and coercion in the context of intimate partner violence (Henry and Powell 2016, Powell et al. 2019).

The widespread reach and permanence of the internet, as well as the lack of anonymity can cause victims of IBSA to experience a number of adverse consequences, which are often more severe for women due to the pervasive sexual double standards in society (Powell and Henry 2019, Powell et al. 2020). Victims experience negative mental health issues, such as anxiety, depression, and PTSD, and they suffer social and financial consequences, including damage to their reputation, breakdown of relationships, and loss of employment (Citron and Franks 2014, Henry and Powell 2015a, Bates 2017). Some victims experience physical threats and further victimisation offline (Bloom 2015, Bates 2017), highlighting the tangible harm caused by IBSA and its connection with sexual violence (McGlynn and Rackley 2017, McGlynn et al. 2019). IBSA is increasingly recognised as a crime and has been criminalised in many countries, including the UK, Australia, Canada, Germany, Italy and 40 out of 50 states in the United States. Many other countries are following efforts for widespread recognition of IBSA as a sexual crime, but those efforts are still ongoing. 
Although there is a growing body of research on IBSA, there is a nascent body of research exploring IBSA perpetration. Pina, Holland and James (2017) were the first to devise an IBSA proclivity scale (specifically examining the "revenge porn" aspect of IBSA between current or former intimate partners) and examined psychological characteristics associated with self-reported likelihood of perpetrating and endorsing IBSA, which have previously been related to committing other forms of online and offline sexual violence. For instance, hostile sexist beliefs are associated with perpetrating online sexual harassment (Tang and Fox 2016) and cyber-bullying in a relationship (Martinez-Pecino and Durán 2019).

Within the literature, TFSV, and IBSA more specifically, have been argued as gendered crimes (Henry and Powell 2015b), and indeed, recent findings from a survey of lifelong perpetration by Australian adults (Powell et al. 2019) showed that males are more likely to engage in IBSA. Additionally, given some of the proposed motivations behind perpetrating IBSA, such as "slut-shaming", relationship retribution and control (Henry and Powell 2016), it was surmised that ambivalent sexism (a construct including hostile and benevolent sexism) could be related to IBSA. Indeed, Pina et al. (2017) found an association between ambivalent sexism and IBSA proclivity and approval. Furthermore, a subsequent replication of the study with a larger and more equally gendered sample found hostile sexism (HS) was an independent predictor of IBSA proclivity, approval, and victim blaming (Pina and Johnson, in preparation).

It has been argued that it is an oversimplification to suggest misogyny is the sole motivation for sexual aggression (Stroud 2014). Aversive personality traits, such as the dark triad, which includes trait narcissism, psychopathy, and Machiavellianism, are related to an indifference to harm caused to others and being exploitative (Jones and Paulhus 2011). Previous research has found these traits are linked to cyberbullying (Goodboy and Martin 2015), romantic revenge (Brewer et al. 2015), and intimate partner cyberstalking (Smoker and March 2017). Therefore, Pina et al. (2017) examined these traits in relation to IBSA. The dark triad traits were positively correlated with IBSA proclivity, but only psychopathy and Machiavellianism were independent predictors in a multiple regression analysis. Additionally, Machiavellianism and narcissism were independent predictors of IBSA approval and enjoyment respectively. This indicates the dark triad personality traits are significant predictors of the likelihood of perpetration and endorsement of this crime. This study therefore aims to provide further validity for this link.

Despite the promising focus on perpetration of IBSA, the psychological pathways that facilitate the perpetration of IBSA remain under-researched. Bandura's (1986) socialcognitive theory could provide a useful framework for the explanation of individuals' engagement in and approval of IBSA. Bandura (1990, 1999) suggested that every individual has their own internal moral standards allowing them to self-regulate their thoughts and behaviours, which inhibits immoral and unethical behaviour. However, these moral standards can be selectively "muted" to reduce the cognitive dissonance felt when engaging in immoral conduct. This process is termed moral disengagement (MD), by which, through eight mechanisms, individuals rationalise and justify perpetrating or approving of harmful behaviours (Bandura 1990, 1999). 
Eight MD mechanisms centre on four aspects of detrimental or inappropriate conduct. A reprehensible conduct itself can be cognitively restructured: this can be done through 1) moral justification, whereby the behaviour is portrayed as serving social or moral purposes; 2) through euphemistic labelling, in which sanitising language is used to disguise the severity of the conduct; or 3) through advantageous comparison, whereby the conduct is compared to more harmful behaviours. The individual's agency in the harmful behaviours can be minimised or obscured through 4) displacement of responsibility, whereby the causes of the behaviour are externally attributed to authorities; or 5) through diffusion of responsibility, in which an individual's contribution to detrimental behaviour is attributed to the group. Furthermore, the detrimental effects of the conduct can be minimised or disregarded through 6) the distortion of consequences. Lastly, two of the disengagement strategies focus on the victim, removing any empathy felt by the perpetrator. This involves 7) dehumanisation, whereby the victims are stripped of human qualities and seen as less than human; or 8) attribution of blame to the victim (Bandura 1990, 1999, Page and Pina 2015).

MD is positively correlated with sexual harassment proclivity (Page and Pina 2018) and cyber-aggression, although the association with cyber-aggression was weaker compared to traditional bullying (Pornari and Wood 2010, Robson and Witenberg 2013). This suggests MD mechanisms facilitate the perpetration of other gendered and online harmful behaviour, hence they could also be implicated in or utilised for the perpetration of TFSV and IBSA. Research has found that non-consensual dissemination of "sexts"(e.g., sexually explicit texting) was more likely to occur if individuals viewed this behaviour as funny (Clancy et al. 2019) - which can be seen as euphemistic labelling (i.e., immoral behaviour is "just a bit of fun" or "banter"; Page et al. 2015).

Additionally, it has been suggested that embodied within rape and sexual harassment myths are MD mechanisms (Bandura 1986, Page and Pina 2015). Carroll (2009), for instance, found higher MD was related to higher rape-supportive attitudes. Victim blame has been closely linked with justifying one's own immoral actions alongside perpetrator exonerating mechanisms (Bandura et al. 1996) - a facet of moral disengagement and common theme in online sexual violence and rape culture (Zaleski et al. 2016). Unsurprisingly, victim blaming attitudes are prevalent in IBSA. Henry, Powell and Flynn (2018) found most participants held attitudes that blamed the victims and minimised the harms of IBSA, with $62 \%$ agreeing the victim is partly responsible for initially sending the image. In addition, the Australian adult population survey (Powell et al. 2019) found that blame and beliefs in erroneous myths about IBSA were predictors of perpetration; consistent with rape myth research (Suarez and Gadalla 2010). Since the aforementioned psychological correlates and personality traits have been linked to TFSV behaviours (e.g. cyber-dating abuse and harassment; Henry and Powell 2015, Woodlock 2017), it is argued that they may also be related to IBSA proclivity, and thus should be investigated. MD may therefore act as a "psychological buffer" that enables individuals to perpetrate acts such as IBSA, weakening saliency of immorality.

\section{The current study}

The tangibility and seriousness of the consequences experienced by the victims of IBSA, the commonality of this phenomenon, and the emerging empirical research to date, indicates the importance of examining the characteristics and social-cognitive processes 
associated with perpetrating IBSA. The current study was a partial replication of Pina et al.'s (2017) research that examined the association between IBSA proclivity and psychological characteristics. This study, however, focused solely on IBSA proclivity and IBSA victim blame scale items.

Additionally, to the best of our knowledge, this is the first study to examine the role of MD in IBSA proclivity and attitudes towards the victims. Specifically, the objectives of this study were (1) to provide further support for the validity and reliability of Pina $e t$ al.'s (2017) findings, (2) to develop and validate a MD image-based sexual abuse scale, and (3) to examine the relationship between MD and the propensity to engage in IBSA. Based on the extant literature, it was hypothesised that (1) the dark tetrad (Dark Triad and Sadism) traits would be independent predictors of IBSA proclivity, (2) ambivalent sexism (hostile and benevolent) would predict victim blaming and IBSA proclivity. We recognise that ambivalent sexism is a measurement of sexist attitudes towards women (benevolent and hostile), and its use is linked to heteronormative paradigms, but we believed it to be appropriate due to the often-gendered nature of IBSA, as well as the presumed hostile and vengeful motivations behind it. In addition, the detrimental effects of IBSA appear to have greater impact on female victims. Furthermore, it was hypothesised that (3) MD would positively correlate with and predict IBSA proclivity and victim blaming as per Page et al. (2015).

\section{Method}

\subsection{Participants and design}

The sample consisted of 126 participants (84 female, 29 male, 13 undisclosed), aged 18 63 years old $(M=25.51, S D=10.85)$. All participants were fluent in English. Participants were recruited via opportunity sampling through advertisement of the study on social media. The present study extends Pina et al. 2017, thus an exploratory, correlational, cross-sectional design was adopted.

\subsection{Materials}

The Short Version of the Ambivalent Sexism Inventory (ASI). The ASI (Glick and Whitehead 2010) was used to measure participants' sexist beliefs. This scale has good psychometric properties (Rollero et al. 2014). Given that the current study comprised of a number of scales, it was considered more pragmatic and appropriate for use than the original 22-item scale. Participants were asked to indicate how much they agreed or disagreed with each item on a 7-point Likert scale $(1=$ strongly disagree, $7=$ strongly agree $)$. Six items represented HS (e.g., Women exaggerate problems they have at work; $\alpha=.85$ ) and six items represented BS (e.g., "Men are incomplete without women"; $\alpha=.74$ ). A sum score was computed for HS and BS, with higher scores indicating more sexist beliefs.

The Short Dark Triad Scale (SD3) The SD3 (Jones and Paulhus 2014) was used to measure participants' socially aversive traits. It consists of 27 items and three subscales measuring Machiavellianism (e.g., "Most people can be manipulated"; $\alpha=.69$ ), Narcissism (excessive self-love; e.g., "People see me as a natural leader", $\alpha=.76$ ) and Psychopathy (e.g., "Payback needs to be quick and nasty"; $\alpha=.76$ ). Participants were 
asked to indicate their agreement with each item on a 5-point Likert scale ( $1=$ strongly disagree, 5 = strongly agree). After relevant items were reverse coded, participants' sum score for each construct was calculated. Higher scores indicate a greater presence of each trait. The overall SD3 reliability was high $\alpha=.85$.

Comprehensive Assessment of Sadistic Tendencies (CAST). The CAST (Buckels and Paulhus 2014) consists of 18 items measuring participants' everyday sadism. Six items measure participants' direct verbal sadistic behaviour (e.g., "I enjoy making jokes at the expense of others"), five items measuring direct physical sadistic behaviour (e.g., "I enjoy tormenting people"), and seven items measuring vicarious sadistic behaviour (e.g., "There's way too much violence in sports"). Eleven filler items were randomly dispersed throughout the CAST scale to obscure the purpose of the measure (Buckels and Paulhus 2014). Participants indicated their agreement to each item on a 7-point Likert scale $(1=$ strongly disagree, $7=$ strongly agree $)$. After relevant items were reverse coded, an overall sadism sum score was calculated $(\alpha=.88)$, with higher scores representing a higher endorsement of everyday sadism.

Moral Disengagement in Image-Based Sexual Abuse Scale (MDiISA). A MD scale was created for the purpose of this research to measure participants' moral disengagement in the context of IBSA. This scale was developed based on pre-existing MD scales (Bandura et al. 1996, Boardley and Kavussanu 2007, Page et al. 2015) and research on IBSA victim blaming and myth acceptance (Hadwin 2017, Lumsden and Morgan 2017). Great care was taken to produce gender neutral items for this scale. After conducting exploratory factor analysis, the scale consisted of 30 items, representing each MD mechanism $(\alpha=.93)$. Moral Justification was measured by 4 items (e.g., " It is OK to post a picture of someone online without their consent if they have treated you unfairly"), Euphemistic Language was measured by 3 items (e.g., "sharing an explicit video or picture of someone online is just part of the online world"), Advantageous Comparison was measured by 4 items (e.g., "considering some people upload explicit images of children, posting a sexually intimate image of an adult online is not that serious"), Displacement of Responsibility was measured by 4 items (e.g., "someone cannot be blamed for uploading footage of a person if there are no regulations to stop them"), Diffusion of Responsibility was measured by 4 items (e.g., "it is unfair to blame a single individual in a group for the distribution of non-consensual images"), Distortion of Consequences was measured by 3 items (e.g., online abuse is no as harmful as abusing someone in real life"), Dehumanisation was measured by 4 items (e.g., "it's ok to post an explicit picture of someone online if they sleep around"), and Attribution of Blame was also measured by 4 items (e.g., "if a person sends a provocative picture, they want it to be shared with others"). All items were measured on a 7 -point Likert scale $(1=$ strongly disagree, $7=$ strongly agree) Following other MD scales, composite mean score was computed with higher scores indicating higher levels of MD.

Revenge Porn Proclivity Scale (RPPS). The RPPS (Pina et al. 2017) was used to assess participants' propensity to engage in and endorse the "revenge porn" aspect of IBSA in former or current relationships. Participants were presented with five gender-neutral scenarios, in which they are the central character, describing the non-consensual distribution of an intimate image of someone and the motivation for doing so. After each scenario, participants were asked seven questions tapping their behavioural proclivity 
(e.g., "In this situation, would you do the same?"); excitement, control, amusement, blame, anger, and regret were measured as part of the scale but with the exception of blame, the others were not analysed due to small numbers of participants. All items were scored on a 5-point Likert scale, the proclivity and blame items scored from 1 (definitely would not) through to 5 (definitely would), and the other items scored from 1 (not at all) to 5 (very). Sum and mean scores were computed for proclivity $(\alpha=.71)$ and blame $(\alpha=.80)$.

\section{Procedure}

This study gained ethical approval from the authors' departmental research ethics committee. All participants completed the questionnaire using Qualtrics. They were directed to an information sheet that described the study, the potential risks and discomforts involved with participation, and their right to withdraw, and full consent was subsequently obtained. Participants were then asked basic demographic questions (e.g., age and gender), followed by the ASI, the SD3 the CAST, the MDiISA scale, and the IBSA proclivity items of the RPPS (see Table 1 for the means and standard deviations of all key variables). After completing these questionnaires, participants were thanked, signposted to relevant helpful resources if they experienced distress, and debriefed.

\section{TABLE 1}

\begin{tabular}{|l|l|l|l|l|}
\hline & Total Mean & Total SD & Males & Females \\
\hline Machiavellianism & 3.05 & 0.64 & 3.39 & 2.94 \\
\hline Psychopathy & 2.07 & 0.67 & 2.70 & 1.89 \\
\hline Narcissism & 2.71 & 0.66 & 3.19 & 2.56 \\
\hline Sadism & 1.85 & 0.64 & 2.54 & 1.61 \\
\hline Hostile Sexism & 2.76 & 0.89 & 2.98 & 2.58 \\
\hline Benevolent Sexism & 2.94 & 0.68 & 3.00 & 2.90 \\
\hline IBSA Proclivity & 1.10 & 0.30 & 1.16 & 1.08 \\
\hline Victim Blame & 2.07 & 1.06 & 2.11 & 2.08 \\
\hline Moral Disengagement & 1.61 & 0.52 & 1.83 & 1.50 \\
\hline
\end{tabular}

Table 1. Main variables.

\section{Results}

\subsection{Preliminary analyses}

First, the normality of the data was checked. Variables exceeding a skewness value of 1.0 indicated skewed data. Log10 transformation was computed for the skewed variable of IBSA proclivity. After computing log10 transformation, only the blame item of the RPPS scale was no longer skewed, which given the nature of the scale was expected. Therefore, the IBSA proclivity was dummy coded and non-parametric tests were conducted. In accordance with Pina et al. (2017) and previous proclivity scale research (Gannon and O'Connor 2011, Alleyne et al. 2015), all participants who did not emphatically state their disagreement (e.g., 1 = definitely would not) were considered as demonstrating a tolerance for IBSA. It was found that $17.5 \%$ of participants demonstrated a tolerance towards committing IBSA (i.e., they scored $>5$ on the proclivity scale) and $71 \%$ placed some of the blame on the victim.

This was also examined by gender by performing a Mann-Whitney $U$ test, with women and men marginally significantly different in their tolerance towards committing IBSA 
(13.1\% of women compared to $27.6 \%$ of men; $U=1032.5 p=.061$ ), and hostile sexism $(U=992.5 p=.061)$, and significantly different on MD $(U=751 p=.002)$, sadism $(U=277$ $p>.001)$, psychopathy $(U=400 p>.001)$, narcissism $(U=568.5 p>.001)$ and Machiavellianism $(U=706.5 p=.001$; see Table 1 for means and SD). Men and women did not differ in their levels of benevolent sexism or victim blaming.

\section{Moral disengagement in Image-Based Sexual Abuse}

Initial item analyses of the MDiISA scale showed evidence of skewness and kurtosis, and the Kolmogoroff-Smirnov test was significant, $p<.001$, hence this scale was nonnormally distributed.

An exploratory factor analysis was computed on the MDiISA scale, using unweighted least squares and direct oblimin rotation. The unweighted least squares method of extraction was used due to the non-normal distribution of the data and small sample size. The Kaiser-Meyer-Olkin's measure of sampling adequacy indicated the data was meritorious at .88 , thus factor analysis was suitable. The scree plot indicated one factor, and after removing items with factor loadings of $<.30$ it accounted for $45.33 \%$ of the variance. The final MDiISA scale consisted of 30 items with factor loadings ranging from .41 to .86 .

\section{IBSA Proclivity and Tolerance}

A Spearman's Rank Order correlation analysis was conducted with all variables to identify significant relationships and inform subsequent regression analysis (Table 2). Out of all the dark personality variables, IBSA proclivity was only correlated with psychopathy and sadism, so these was entered into a Binary Logistic regression along with MDiISA and Victim Blame. The regression model was statistically significant and explained between 22\% (Cox and Snell R Square) and 35\% of the variance (Nagelkerke R Square) of IBSA proclivity; with victim blame (Wald $\chi^{2}=7.42, p=.006$ ) and MDiISA (Wald $\chi^{2}=6.00, p=.014$ ) being significant predictors of IBSA proclivity but none of the dark personality traits being predictors of proclivity. Benevolent and Hostile Sexism were not correlated with IBSA proclivity in this sample and were not entered in the regression, hence our hypotheses 1 and 2 were not supported. Sadism was a significant predictor of IBSA proclivity (Wald $\chi^{2}=3.87, p=.049$ ) when MD was removed from the model. MDiISA was also found to be the only significant predictor of victim blame $(\beta=2.32, p=.028$; entered simultaneously with psychopathy and sadism), but that model only explained $8.5 \%$ of the variance, confirming hypothesis 3 . 
TABLE 2

\begin{tabular}{|l|l|l|l|l|l|l|l|l|}
\hline \multicolumn{1}{|c|}{$\mathbf{1}$} & $\mathbf{2}$ & $\mathbf{3}$ & $\mathbf{4}$ & $\mathbf{5}$ & $\mathbf{6}$ & $\mathbf{7}$ & $\mathbf{8}$ \\
\hline 1) BS & - & & & & & & & \\
\hline 2) HS & $.35^{* *}$ & - & & & & & & \\
\hline 3) Machiavellianism & $.23^{*}$ & $.35^{* *}$ & - & & & & & \\
\hline 4) Psychopathy & .11 & $.27^{* *}$ & $.44^{* *}$ & - & & & & \\
\hline 5) Narcissism & $.28^{* *}$ & .17 & $.34^{* *}$ & $.41^{* *}$ & - & & & \\
\hline 6) CAST & .05 & $.26^{* *}$ & $.42^{* *}$ & $.71^{* *}$ & $.35^{* *}$ & - & & \\
\hline 7) MDiISA & $.22^{*}$ & $.30^{* *}$ & $.35^{* *}$ & $.45^{* *}$ & $.33^{* *}$ & $.52^{* *}$ & - & \\
\hline 8) Victim blame & $.24^{* *}$ & .14 & $.24^{* *}$ & $.30^{* *}$ & -.07 & $.28^{* *}$ & $.30^{* *}$ &.- \\
\hline 9) IBSAproclivity & .12 & .16 & .14 & $.18^{*}$ & .11 & $.32^{* *}$ & $.37^{* *}$ & $.40^{* *}$ \\
\hline Note: p <.05*, p <.01** & & & & & & & \\
\hline
\end{tabular}

\section{Discussion}

The present study aimed to contribute to the nascent research on the perpetration of IBSA. It was a partial replication of Pina et al.'s (2017) research which utilised a proclivity scale to examine characteristics in relation to their likelihood of perpetrating IBSA. Additionally, this study is presented as the first to examine the role of MD mechanisms in the context of IBSA.

The IBSA proclivity findings $(17.5 \%)$ were lower in this research compared to previous findings, (e.g., 28.6\% in Pina et al. 2017) where a higher proportion of participants indicated a tolerance towards committing IBSA. It is nevertheless, quite common that tolerance is higher than direct intentions to perpetrate IBSA (as shown in Pina et al. 2017 high levels of approval and enjoyment compared to lower proclivity). Given that IBSA and related behaviours (e.g., upskirting) are part of ongoing discourse, media coverage and legislative change (particularly in the UK where the majority of the sample originated), this could indicate that people are becoming more aware of these behaviours and the harm caused, thus are less likely to indicate they would engage in them. We also found gender differences for most key variables; men were more likely to express a likelihood to perpetrate IBSA and they were more likely to morally disengage than women. They also self-reported higher scores for all dark personality traits (e.g., Machiavellianism, sadism, psychopathy and narcissism. This, however, warrants further investigation to see if this can be replicated in future studies with more even sample distribution and to determine if the reasons given are different for men compared to women.

Victim blaming, although not significantly different between genders, was present to some proportion for $71 \%$ of our sample. Research has produced mixed findings for the gender differences in IBSA victim blaming (Bothamley and Tully 2017, Powell et al. 2019), hence further research is necessary. It is difficult to directly compare these findings to previous research. In Pina et al.'s (2017) research, this item was aggregated together with anger and regret to form an approval subscale, however in this study victim blame was examined separately. Nevertheless, it seems whilst the percentage of people's 
likelihood to commit IBSA is low, the percentage of people demonstrating some level of IBSA victim blaming is higher (in this study we didn't analyse other items of the RPPS such as excitement or amusement, due to low power, although basic means did show significantly higher proportions of both; e.g., Pina et al. 2017). This can have a detrimental effect on victims, in terms of the facilitating role of bystanders (Pina et al. 2017), not only in the dissemination of the images, but also in creating a culture where the responsibility is placed on the victims rather than the perpetrators. This demonstrates the importance of education around IBSA and the role of bystanders in the phenomenon.

With regards to the association between individual characteristics and a tolerance towards IBSA, hypotheses were not supported. Contrary to expectations, Machiavellianism, psychopathy and narcissism were not predictors of IBSA proclivity, thus contradicting previous findings on TFSV (Goodboy and Martin 2015, Pina et al. 2017, Smoker and March 2017). Sadism was a significant predictor of IBSA proclivity when MD was not included in the model. This brings to the fore considerations about the conceptual similarity of MDiISA as a measurement with IBSA proclivity that will need to be examined further in future research using the MDiISA. It would be also interesting for further research to examine if there are differences in the modes of perpetration of, and motivations for IBSA perpetration and self-reported moral disengagement. Unexpectedly, HS and BS, were not predictors of IBSA proclivity or blaming the victim. This was surprising considering previous research (Pina et al. 2017), and not including a measurement of sexism towards men (e.g., AMI, Glick and Whitehead 2010) may have missed significant nuances in the sample's responses. Again, MD or other variables may be accounting for much of the variance of forms of sexism.

Regarding the second aim of this paper, which was to develop and validate a moral disengagement scale in the context of IBSA, this was achieved. The MDiISA had excellent internal consistency, and as in previous research, factor analysis revealed the unidimensional structure of the MDiISA scale (Caprara et al. 2009, Page et al. 2015). Although confirmatory factor analysis needs to be conducted, this demonstrates the items in this scale could represent a common, underlying trait or cognition that makes people prone to use these mechanisms to justify perpetrating IBSA (Page et al. 2015).

Supporting our $3^{\text {rd }}$ hypothesis, the MDiISA scale was a predictor of IBSA proclivity, consistent with Bandura's $(1986,1999)$ social cognitive theory and previous MD research (Pornari and Wood 2010, Robson and Witenberg 2013, Page et al. 2015, Page and Pina 2018). This indicates that people who expressed greater levels of MD expressed a greater tolerance to perpetrating IBSA. Although MDiISA was presented before the RPPS, we cannot ascertain from this study if MD was a direct antecedent or cause of IBSA proclivity. Determination of antecedents requires experimental or longitudinal research, which would greatly enrich our knowledge of this behaviour. For instance, experimental research could manipulate MD to examine its effects on IBSA proclivity, or examine its potential mediation linking motivation for engaging in IBSA and proclivity or support for it.

Moreover, MDiISA was a predictor of victim blaming, consistent with Page et al.'s (2015) findings, which showed that MD in the context of workplace sexual harassment increased the attribution of blame to the female complainant. This provides evidence for victim-centred MD strategies, which allow the person to further exonerate their, or 
someone else's, behaviour. It could be argued that this scale reflects myths relating to IBSA rather than a cognitive restructuring of the transgressive behaviour through these MD mechanisms. However, previous research has highlighted that despite their conceptual similarity, myth acceptance and moral disengagement are empirically different constructs (Page et al. 2015). Future research could examine the discriminant validity between this scale and the newly established Sexual Image-based Abuse Myth Acceptance scale (SIAMA; Powell et al. 2019).

This study, although informative, has some considerable limitations. Although selfreport questionnaires provide participants with more anonymity, which can be beneficial for sensitive topics, some participants may try to hide their true preferences and attitudes due to the sensitive and stigmatising nature of the questions. Thus, our findings are vulnerable to social desirability bias. Nevertheless, this is a limitation that most research on this topic faces, and we recommend using an impression management scale in future studies.

An additional limitation concerns participants' self-reported proclivity. Although this provides us with an idea of who has a tolerance towards this behaviour, it does not mean these people will perpetrate IBSA. Therefore, examining these characteristics and the use of MD mechanisms with a forensic sample (with actual perpetrators of IBSA) is important. Moreover, the RPPS currently focuses on revenge as the motivation for engaging in IBSA and in the context of (existing or former) relationships, when the literature has identified different motivations for engaging in this behaviour. It could be argued this is a limitation of this study and the RPPS more specifically. However, considering Pina et al. (2017) and subsequent research have been the first to examine IBSA perpetration, it has provided a good basis for future research to build upon. It would be interesting to explore whether a similar relationship would be found between personality characteristics, MD, and other forms of IBSA, by including scenarios depicting different motivations and perpetrator-victim relationships.

Lack of a measure of sexism towards males and generally the context of this study can arguably be considered heteronormative and gendered, despite the care in creating gender neutral items for both the MDiISA and RPPS. Finally, the small sample of participants, large age range (18-63 years.) and the cross-sectional design of the study are significant limitations. Despite valuable information regarding people's propensity to commit IBSA and their characteristics, they do represent only 17.5\% (22 individuals out of 126) of the total sample, and thus, any conclusions need to be cautiously considered.

In summary, despite the limitations, the present research is novel in its examination of MD in IBSA. It supports the reliability and validity of the RPPS and the relationship between certain beliefs and IBSA perpetration and provides an important insight into psychological processes involved in committing this behaviour. Additionally, it provides a good basis for further research to extend upon and examine other facilitating or inhibiting processes involved in perpetrating IBSA. Lastly, this study highlights the importance of education about the harm caused and attitudes that serve to exonerate and justify IBSA behaviours. Consistent educational efforts and a change in everyday discourse about IBSA have the potential to reduce the accessibility of mechanisms of $\mathrm{MD}$, and consequently IBSA tolerance and proclivity. 


\section{References}

Alleyne, E., et al., 2015. Adult-perpetrated animal abuse: development of a proclivity scale. Psychology, Crime \& Law [online], 21(6), 570-588. Available from: https://doi.org/10.1080/1068316X.2014.999064 [Access 12 July 2021].

Bandura, A., 1986. Social foundations of thought and action: A social cognitive theory. Englewood Cliffs: Prentice Hall.

Bandura, A., 1990. Selective activation and disengagement of moral control. Journal of Social Issues [online], 46(1), 27-46. Available from: https://doi.org/10.1111/j.15404560.1990.tb00270.x [Access 5 July 2021].

Bandura, A., 1999. Moral disengagement in the perpetration of inhumanities. Personality and Social Psychology Review [online], 3(3), 193-209. Available from: https://doi.org/10.1207/s15327957pspr0303 3 [Access 5 July 2021].

Bandura, A., et al., 1996. Mechanisms of moral disengagement in the exercise of moral agency. Journal of Personality and Social Psychology, 71(2), 364-374.

Bates, S., 2017. RP and mental health: A qualitative analysis of the mental health effects of RP on female survivors. Feminist Criminology [online], 12(1), 22-42. Available from: https://doi.org/10.1177/1557085116654565 [Access 5 July 2021].

Bloom, S., 2015. No vengeance for "RP" victims: Unraveling why this latest femalecentric, intimate-partner offense is still legal, and why we should criminalize it. Fordham Urban Law Journal [online], 42(1), 233-289. Available from: https://ir.lawnet.fordham.edu/ulj/vol42/iss1/2 [Access 5 July 2021].

Boardley, I.D., and Kavussanu, M., 2007. Development and validation of the moral disengagement in sport scale. Journal of Sport and Exercise Psychology, 29(5), 608628.

Bothamley, S., and Tully, R.J., 2017. Understanding revenge pornography: public perceptions of revenge pornography and victim blaming. Journal of Aggression, Conflict and Peace Research, 10(1), 1-10.

Brewer, G., et al., 2015. Dark Triad traits, infidelity and romantic revenge. Personality and Individual Differences, 83, 122-127.

Buckels, E., and Paulhus, D.L., 2014. Comprehensive assessment of sadistic tendencies (CAST) (Unpublished measure). Vancouver: University of British Columbia.

Caprara, G.V., et al., 2009. Assessing civic moral disengagement: Dimensionality and construct validity. Personality and Individual Differences [online], 47(5), 504-509. Available from: https://doi.org/10.1016/j.paid.2009.04.027 [Access 5 July 2021].

Carroll, J.A., 2009. Impact of moral judgment and moral disengagement on rape-supportive attitudes in college males [online]. Doctoral dissertation. Philosophy. Tuscaloosa: University of Alabama. Available from: https://ir.ua.edu/handle/123456789/623 [Access 5 July 2021].

Citron, D.K., and Franks, M.A., 2014. Criminalizing revenge porn. Wake Forest Law Review [online], 49, 345-391. Available from: 
https://repository.law.miami.edu/cgi/viewcontent.cgi?article $=1059 \&$ context $=$ fac a rticles [Access 5 July 2021].

Clancy, E.M., Klettke, B., and Halford, D.J., 2019. The dark side of sexting. Factors predicting the dissemination of sexts. Computers in Human Behavior, 92, 266-272.

Gannon, T.A., and O'Connor, A., 2011. The development of the Interest in Child Molestation Scale. Sexual Abuse, 23(4), 474-493.

Glick, P., and Whitehead, J., 2010. Hostility toward men and the perceived stability of male dominance. Social Psychology, 41(3), 177-185.

Goodboy, A.K., and Martin, M.M., 2015. The personality profile of a cyberbully: Examining the Dark Triad. Computers in Human Behavior [online], 49, 1-4. Available from: https://doi.org/10.1016/j.chb.2015.02.052 [Access 5 July 2021].

Hadwin, J., 2017. Victim Blaming and Third-person Effect: A Comparative Analysis of Attitudes for RP and Sexual Assault [online]. Master's thesis. Science. Stillwater: University of Oklahoma. Available from: https://shareok.org/bitstream/handle/11244/54533/Hadwin okstate 0664M 15165 .pdf? sequence $=1$ [Access 5 July 2021].

Henry, N., and Powell, A., 2015a. Beyond the "sext": Technology-facilitated sexual violence and harassment against adult women. Australian \& New Zealand Journal of Criminology [online], 48(1), 104-118. Available from: https://doi.org/10.1177/0004865814524218 [Access 5 July 2021].

Henry, N., and Powell, A., 2015b. Embodied harms: Gender, shame and technologyfacilitated violence. Violence Against Women [online], 21(6), 758-779. Available from: https://doi.org/10.1177/1077801215576581 [Access 5 July 2021].

Henry, N., and Powell, A., 2016. Sexual violence in the digital age: The scope and limits of criminal law. Social and Legal Studies [online], 25(4), 397-418. Available from: https://doi.org/10.1177/0964663915624273 [Access 5 July 2021].

Henry, N., Flynn, A., and Powell, A., 2019. Image-Based Sexual Abuse: Victims and Perpetrators. Trends and Issues in Crime and Criminal Justice [online], no. 572. Available from: https://www.aic.gov.au/sites/default/files/202005/imagebased sexual abuse victims and perpetrators.pdf [Access 5 July 2021].

Henry, N., Powell, A., and Flynn, A., 2018. Not Just "Revenge Pornography": Australians' Experiences of Image-Based Abuse. A Summary Report. Melbourne: RMIT University.

Jones, D.N., and Paulhus, D.L., 2011. Differentiating the Dark Triad within the interpersonal circumplex. In: L.M. Horowitz and S. Strack, eds., Handbook of interpersonal psychology: Theory, research, assessment, and therapeutic interventions. New York: Wiley \& Sons, 249-269.

Jones, D.N., and Paulhus, D.L., 2014. Introducing the Short Dark Triad (SD3): A brief measure of dark personality traits. Assessment, 21(1), 28-41.

Lumsden, K., and Morgan, H., 2017. Media framing of trolling and online abuse: silencing strategies, symbolic violence, and victim blaming. Feminist Media Studies, 17(6), 926-940. 
Martinez-Pecino, R., and Durán, M., 2019. I love you but I cyberbully you: The role of hostile sexism. Journal of Interpersonal Violence [online], 34(4). Available from: https://doi.org/10.1177/0886260516645817 [Access 5 July 2021].

McGlynn, C., and Rackley, E., 2017. Image-based sexual abuse. Oxford Journal of Legal Studies, 37(3), 534-561.

McGlynn, C., Rackley, E., and Johnson, K., 2019. Shattering Lives and Myths: A Report on Image Based Sexual Abuse [online]. Australian Research Council. Available from: https://s3-eu-west-2.amazonaws.com/victcomm2-prod-storage119w3o4kq2z48/uploads/2019/07/ShatteringLivesandMythsFINALJuly2019.pdf [Access 5 July 2021].

Page, T.E., and Pina, A., 2015. Moral disengagement as a self-regulatory process in sexual harassment perpetration at work: A preliminary conceptualization. Aggression and Violent Behavior, 21, 73-84.

Page, T.E., and Pina, A., 2018. Moral disengagement and self-reported harassment proclivity in men: the mediating effects of moral judgment and emotions. Journal of Sexual Aggression [online], 24(2), 1-24. Available from: https://doi.org/10.1080/13552600.2018.1440089 [Access 5 July 2021].

Page, T.E., Pina, A., and Giner-Sorolla, R., 2015. “It was only harmless banter!” The development and preliminary validation of the moral disengagement in sexual harassment scale. Aggressive Behavior, 42(3), 254-273.

Pina, A., and Johnson, A. (in preparation). The role of personality traits and RP myth acceptance on the proclivity to engage in RP. Manuscript prepared for publication.

Pina, A., Holland, J., and James, M., 2017. The malevolent side of RP proclivity: dark personality traits and sexist ideology. International Journal of Technoethics (IJT), $8(1), 30-43$.

Pornari, C.D., and Wood, J., 2010. Peer and cyber aggression in secondary school students: The role of moral disengagement, hostile attribution bias, and outcome expectancies. Aggressive Behavior: Official Journal of the International Society for Research on Aggression, 36(2), 81-94.

Powell, A., 2010. Configuring consent: Emerging technologies, unauthorized sexual images and sexual assault. Australian \& New Zealand Journal of Criminology, 43(1), 76-90.

Powell, A., 2015. Seeking rape justice: Formal and informal responses to sexual violence through technosocial counter-publics. Theoretical Criminology, 19(4), 571588.

Powell, A., and Henry, N., 2018. Policing technology-facilitated sexual violence against adult victims: Police and service sector perspectives. Policing and Society, 28(3), 291-307.

Powell, A., and Henry, N., 2019. Technology-facilitated sexual violence victimization: Results from an online survey of Australian adults. Journal of Interpersonal Violence, 34(17). 
Powell, A., et al., 2019. Image-based sexual abuse: The extent, nature, and predictors of perpetration in a community sample of Australian adults. Computers in Human Behavior, 92, 393-402.

Powell, A., et al., 2020. Image-based sexual abuse: An international study of victims and perpetrators: A summary report [online]. Melbourne: RMIT University. Available from: https://research.monash.edu/en/publications/image-based-sexual-abuse-aninternational-study-of-victims-and-pe [Access 5 July 2021].

Rentschler, C.A., 2014. Rape culture and the feminist politics of social media. Girlhood Studies [online], 7, 65-82. Available from: https://doi.org/10.3167/ghs.2014.070106 [Access 5 July 2021].

Robson, C., and Witenberg, R.T., 2013. The influence of moral disengagement, morally based self-esteem, age, and gender on traditional bullying and cyberbullying. Journal of School Violence, 12(2), 211-231.

Rollero, C., Glick, P., and Tartaglia, S., 2014. Psychometric properties of short versions of the ambivalent sexism inventory and ambivalence toward men inventory. TPM: Testing, psychometrics, methodology in applied psychology [online], 21(2), 149159. Available from: https://core.ac.uk/download/pdf/301960642.pdf [Access 5 July 2021].

Smoker, M., and March, E., 2017. Predicting perpetration of intimate partner cyberstalking: Gender and the Dark Tetrad. Computers in Human Behavior, 72, 390396.

Stroud, S.R., 2014. The dark side of the online self: A pragmatist critique of the growing plague of RP. Journal of Mass Media Ethics [online], 29(3), 168-183. Available from: https://doi.org/10.1080/08900523.2014.917976 [Access 5 July 2021].

Suarez, E., and Gadalla, T.M., 2010. Stop blaming the victim: A meta-analysis on rape myths. Journal of Interpersonal Violence, 25(11), 2010-2035.

Tang, W.Y., and Fox, J., 2016. Men's harassment behavior in online video games: Personality traits and game factors. Aggressive Behavior, 42(6), 513-521.

Tungate, A., 2014. Bare necessities: The argument for a "RP" exception in Section 230 immunity. Information E Communications Technology Law [online], 23(2), 172-188. Available from: https://doi.org/10.1080/13600834.2014.916936 [Access 5 July 2021].

Walker, K., and Sleath, E., 2017. A systematic review of the current knowledge regarding revenge pornography and non-consensual sharing of sexually explicit media. Aggression and Violent Behaviour, 36, 9-24.

Woodlock, D., 2017. The abuse of technology in domestic violence and stalking. Violence Against Women, 23 (5), 584-602.

Zaleski, K.L., et al., 2016. Exploring rape culture in social media forums. Computers in Human Behavior, 63, 922-927. 


\section{Appendix. Moral disengagement in image-based sexual abuse scale (MDiISA)}

( 1 = Strongly disagree, $7=$ Strongly agree $)$

Moral Justification

1. Those who complain about online abuse are just too easily offended

2. If someone is unfaithful, they deserve some form of punishment

3. It is okay to post a picture of someone online without their consent if they have treated you unfairly

4. It is flattering to have your picture shared online

Euphemistic language

1. Posting a picture of someone online is just a bit of fun

2. Photoshopping someone's face onto a naked body is just a joke

3. Sharing an explicit video or picture of someone online is just part of the online world

Advantageous comparison

1. Compared to the abuse that happens in "real life", posting a picture without consent online is not that serious

2. Posting a picture of someone online is no big deal when you consider others sexually assault people

3. Considering some people upload explicit images of children, posting a sexually intimate image of an adult online is not that serious

4. Sharing an explicit image of someone online once is not that serious compared to those who would do that systematically

Displacement of responsibility

1. Someone cannot be blamed for uploading footage of a person if there are no regulations to stop them

2. People should not be blamed for uploading pictures of others without their consent, when celebrities also do it

3. The internet is full of sexual content, so one cannot be blamed for sharing it

4. If someone is being pressured to take revenge, it is hardly surprising when they upload pictures and videos of people without their consent

Diffusion of responsibility

1. It is unfair to condemn those who have engaged in image based abuse (a.k.a revenge porn) if its common practice and everyone seems to do it

2. The person who engages in online abuse cannot be blamed if their friends encouraged them to do it

3. If a person only suggests distributing a picture or video of someone online, it is not their fault if their friends upload it

4. It is unfair to blame a single individual in a group for the distribution of nonconsensual images

Distortion of consequences

1. Online abuse is not as harmful as abusing someone in "real life" 
2. The consequences of online abuse are exaggerated

3. Revenge porn rarely happens

Dehumanisation

1. Some people lack feelings so online abuse doesn't hurt them

2. It is okay to post an explicit picture of someone online if they sleep around

3. An attractive person should expect pictures of their body to be shared online

4. If someone is unattractive, they should realise that they have no right to complain if people are laughing at them

Attribution of blame

1. If a person sends a provocative picture, they want it to be shared with others

2. Someone who posts regularly on social media is not entitled to online privacy and should expect their pictures to be shared

3. People who get their pictures posted online usually do something to deserve it

4. In a relationship if one person cheats or breaks up with the other, it is their fault if their pictures are then shared online 